УДК 378.147

\title{
TEACHING TECHNICAL UNIVERSITY STUDENTS THE STRATEGIES OF PROFESSIONAL COMMUNICATION AT THE FOREIGN LANGUAGE CLASSES
}

\author{
(C) L. G. Yusupova ${ }^{1} *$, E. P. Zheltova ${ }^{2}$ \\ ${ }^{1}$ Ural State Mining University \\ 30 Kuybyshev Street, 620144 Yekaterinburg, Russia. \\ ${ }^{2}$ Bonch-Bruevich Saint-Petersburg State University of Telecommunications \\ 22 Bolshevikov Avenue, 193232 Saint Petersburg, Russia. \\ Phone: +7 (343) 2572547. \\ *Email: lyalyax@bk.ru
}

\begin{abstract}
The authors of the article stress the importance of teaching students the rules of effective communication, its strategies and tactics for the success of communicative behavior in a multicultural society. Special attention is payed to learning of business communication situations and the rules of communicative behavior. In the developed scheme, the types and goals of effective communication, as well as reflexive, cognitive, and communicative strategies are presented. The carried out analysis shows the dynamics of the estimation of the students' skills of using communicative strategies.
\end{abstract}

Keywords: communicative strategy, communicative tactics, intercultural competence, crosscultural business situations, effective communication.

One of the leading trends in modern education is its orientation towards multiculturalism with a foreign language being an instrument of subcultural professional interaction and a means of developing a specialist's personality in the situations of professional cooperation with the representatives of other cultures [1]. A professionally oriented university course aims at teaching students the peculiarities of speech and communication activities in the situations of business communicative interaction.

In this regard, a foreign language acquisition in a new paradigm is viewed as the development of not only communicative but also intercultural foreign language competence, namely, the ability to relate linguistic means to the tasks and conditions of communication taking into account social norms of behavior in the process of communication with the representatives of other cultures.

The analysis of the English language learning by the students of nonlinguistic qualifications convincingly demonstrates that the greatest difficulties in mastering their intercultural competence are caused by the situations of business communication such as presentation of material, written and verbal exchange of information, expression of opinion, discussion, establishment and maintenance of personal contacts, interviews, meetings and negotiations, etc. [2-3]. Students have limited knowledge of communicative strategies and language means to establish an interactive communication [4-5].

In this respect, it is necessary to draw students' special attention to the situations of business communication, such as the establishment of contacts, negotiations, interviews, consulting, conflict management, etc. as well as to the development of communicative skills such as the choice and effective use of various active communicative strategies and tactics, interpretation and understanding of the views and behavior of the representatives of other cultures.

According to $\mathrm{N}$. Zhukov, in particular, the basic rules governing communicative behavior are 1) the rules of communicative etiquette; 2 ) the rules of communicative impact coordination; 3) the rules of selfdenial. For instance, the tactics for a business talk includes getting into contact, setting goals, exchanging views, getting out of contact [6]. Understanding the world of professional communication and its rules as well as developing skills of identification and production of speech patterns in diverse situations of business cooperation mean training in strategies of professional communicative interaction, adequate speech behavior, and effective influence on a partner. Having studied in detail the models of communicative behavior in some foreign and domestic researchers' papers [7-10], we have schematically defined the types and purposes of effective communication below in Fig. 1 .

Considering the main characteristics of active listening in business communication, it is possible to distinguish 3 basic categories of skills being presented in all communicative strategies (consulting, interviewing, conducting negotiations, making requests, managing conflicts): maintaining communication, managing communication, establishing contacts of interpersonal relations. According to P. Adler, active listening includes both verbal and non-verbal tactics: linguistic reflection, rephrasing, identification of emotions and summarizing [11]. Linguistic reflection is an exact reproduction of the speaker's words to show that he has been heard and understood. For example: So, you have said that you were upset. Is that right? You were excited. Paraphrasing is used to convey the words of the speaker in one's own words in order to confirm that the partner has been well understood and to demonstrate the understanding of his thought. In this case, disjunctive questions are also effective: You'll be in the office tomorrow, won't you? As a rule, paraphrasing is used if the expressed thought is especially important and its understanding must be confirmed. For example: As far as I have got, your idea is original. Paraphrasing gives an opportunity to connect different topics of conversation and to create the atmosphere of empathy and mutual understanding. The tactics of identification of emotions is used along with paraphrasing. The purpose of this tactics is to create the atmosphere of trust and confidence by recognizing the emotions of the other party and giving them external expression, as well as showing respect to the partner. For example: "I see your feelings", "You look excited, what troubles you?", "That sounds terrible / feasible / very reasonable". 


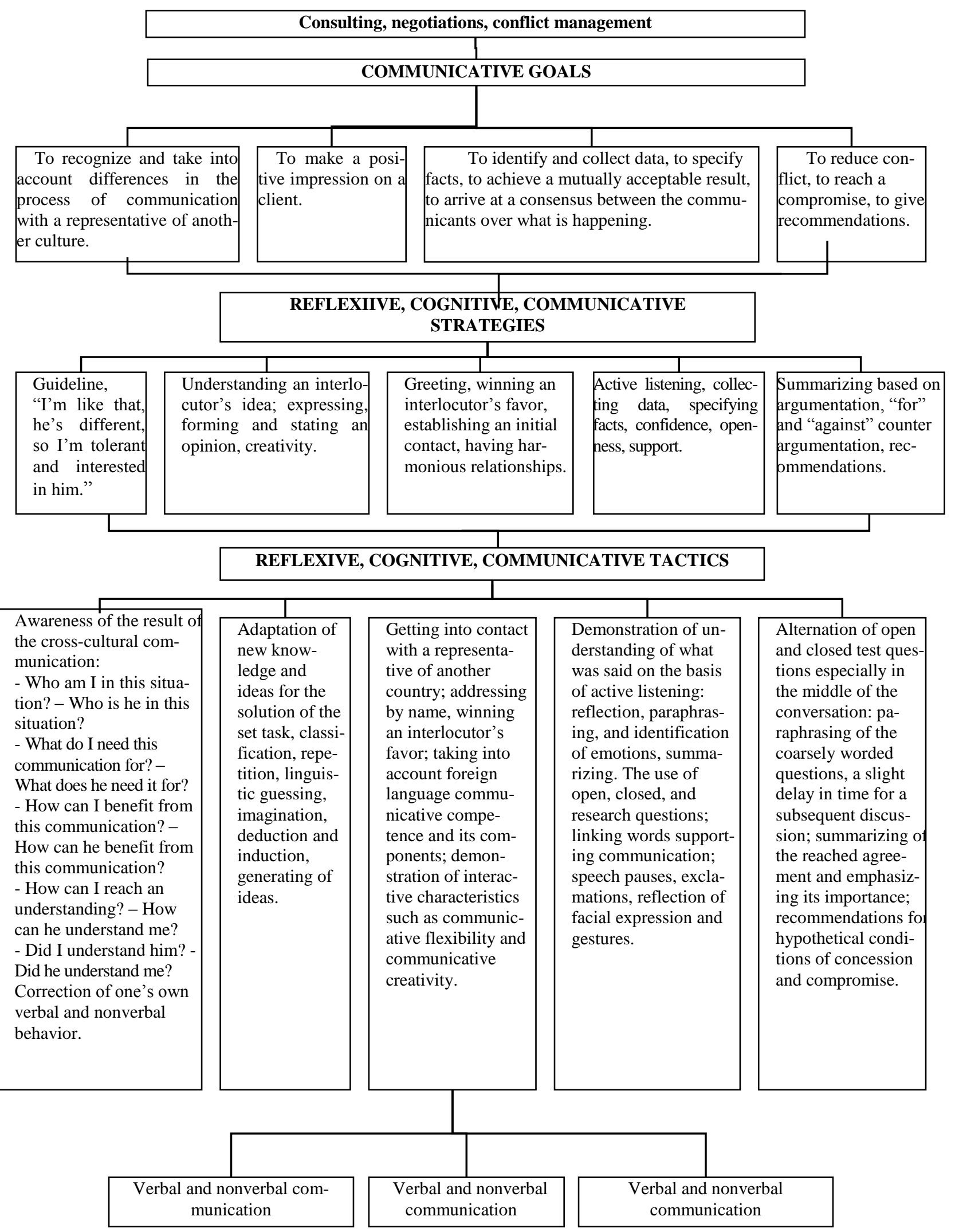

Fig.1. Strategies of effective communication. 
The tactics of summarizing aims at summing up a prolonged exchange of information, especially if it includes a block of ideas. Therefore, the communicative goal of summarizing is not only the summary of information but also the strengthening of trust between the parties, since the one who summarizes demonstrates his careful attention to his partner's words. For example: "So, to recap we can point out the following issues: 1, 2, 3".

Verbal communication in the professional sphere will be incomplete without adequate nonverbal means creating a positive atmosphere of trust, openness, and support. As M. Hammer notes, the most acceptable nonverbal means are speech pauses, words of cheers, reflection of facial expressions and gestures, characteristics of facial expressions and gestures [12].

Speech pauses are not just empty spaces but semantic spaces giving time to think, consider, collect thoughts, and control emotions. However, the length of pauses (more than 1 minute) may complicate the situation.

Active listening strategies help to communicate more effectively. The words of cheer such as "Aha!", "Oh, yes", "Yeah", "Right", "Got you" demonstrate the involvement in the conversation. Reflection of the other person's body language by means of a posture, facial expression, eye contact and distance between the interlocutors is associated with the expressiveness and reaction of a face, tension or relaxation of a posture (in relation to national and cultural norms).

Sound characteristics such as loudness and pitch of a voice, tempo and rhythm of speech are of great importance. For example, an excessively loud voice and assertive or aggressive tone are unacceptable in the business culture of England or Canada but appropriate in that of Russia.

Questions are very important for a dialogue. The questions are divided into three main categories: open, closed and research ones. Open-ended questions are strategic in nature. They encourage a partner to give answers, reveal his interests, provide unexpected information, introduce clarity, and give the key to the understanding of plans and intentions. For example:
"What is your opinion about this work?" Research questions urge a partner to clarify. They are useful for those topics which have not been discussed during the conversation, or if the partner tries to avoid these topics. For example: "Could you tell me about it in more details?", "Can you specify your position on the point?" (The question clarifies the opinion.) And it can also get another opinion. For example: "What was particularly appealing to you in that project?" Questions about the consequences are also effective. For example: "What if you contact Mr. Brown right now? ". Closed questions are expected to provide "yes" or "no" answer sand are used to confirm specific quantifiable information [12]. For example: "Did you set up a new company last year?"

To have an open dialogue, three methods to communicate personal information are of great importance: facts from personal life (references to knowledge, experience, which relate to the topic of communication and contribute to confidence building); references to personal values and beliefs that are important for the partner's personality and express his moral principles which he is used to following; references to aspirations and fears (indications of personal goals, interests, sometimes weaknesses).

The questionnaire survey of the students has revealed that the knowledge of the rules, strategies and tactics of effective communication is of crucial importance to them.

The problems to be solved were created by simulating typical situations of professional cooperation that arise in business communication in the Englishlanguage society through the introduction of the Case Study [13-14] technology. Acting out and solving problem situations, students in two experimental groups (30 people) learnt special speech patterns, practiced communicative strategies with the aim of reaching an agreement to solve practical tasks.

Self-Assessment Checklist has showed the dynamics in the students' ability to use communicative communication strategies:

Communicative strategies

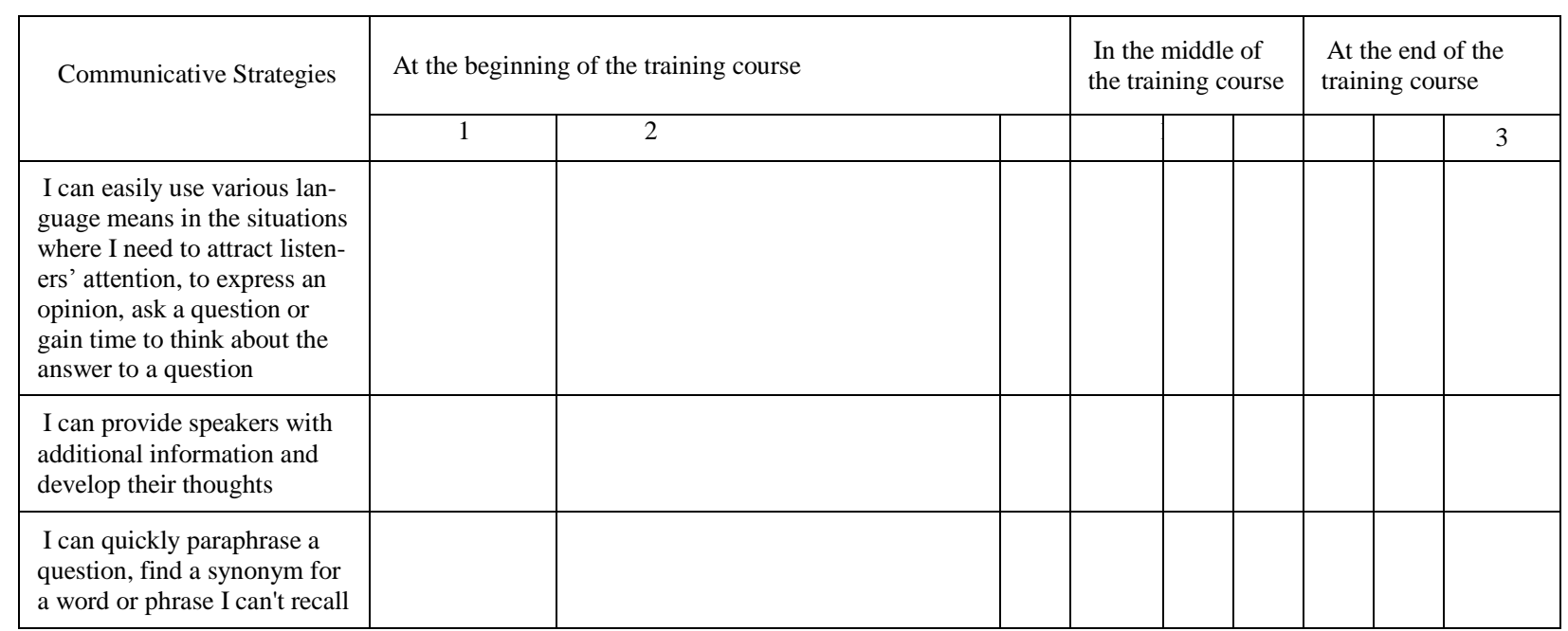


The analysis was carried out during the semester. The students assessed themselves (1), and they were also assessed by their groupmates (2) and a teacher (3). At the end of the first semester, they completed a questionnaire and wrote a test on the studied material where they were to ask questions, to paraphrase, to summarize, and to show theoretical knowledge of the rules of communicative etiquette characteristic of professional intercultural communication. In the experimental group, the average score of activities was different by 7 points as compared to that of the control group, where the interactive method of Case Study was not used. In the experimental group, the academic achievements increased by $15 \%$, while in the control group their increase was only $5 \%$. The questionnaire survey of the students revealed that a new organization of the educational process allowed the students of the experimental group to acquire more profound knowledge of the situations of business communication and contributed to the development of their ability to use the rules of effective communication, different types of communicative strategies and tactics.

\section{LITERATURE}

1. Federal State Educational Standard of Higher Education: Federal Law of the Russian Federation of 9 February, 2016. №91.

2. Zheltova E. P. Development of intercultural competence of technical university students in the process of foreign language teaching: dis. ... cand. ped. scs / E. P. Zheltova. Magnitogorsk, 2006. URL: http://www.dissercat.com/content/razvitiemezhkulturnoi-kompetentsii-studentov-tekhnicheskogouniversiteta-v-protsesse-izuche (reference date: 27.12.2017).

3. Yusupova L. G. Development of readiness of students of nonlinguistic specialties of higher education institution to crosscultural communication: dis. ... cand. ped. scs. Chelyabinsk,
2008. URL: http://search.rsl.ru/ru/record/01004112893 (reference date: 27.12 .2017 ).

4. Zheltova E. P. Strategies and tactics as a means of developing students' intercultural competence while teaching a foreign language in a non-linguistic university / "Vestnik of KSU named after NA. Nekrasov. Series: Pedagogics. Psychology. Social Work. Youth Studies. Social Kinetics." 2014. Vol. 20. №3. P. 218.

5. Zheltova E. P., Yusupova L. G. Intercultural communication: hot topics and prospects for change in non-linguistic universities. Russian humanitarian journal. 2017. Vol. 6. №4. C. 339348. DOI: 10.15643 .

6. Zhukov Yu. N. Efficiency of business communication. M.: Znaniye. 1998.64 p.

7. Sternin I. A. Models of the description of communicative behavior. Voronezh, 2000. 27 p.

8. Bosova L. M. On the interactive competence of a specialist in the situations of professional intercultural communication [Electronic resource]. URL: http://elib.altstu.ru/elib/books/ Files/pa1998_1/pages/12/pap_12.html (reference date: 27.11.2017)

9. Byram M., Nicols A., Stevens D. Developing Intercultural Competence in Practice. Great Britain by the Cronwell Press Ltd., 2001. 283 p.

10. Stanton N. Mastering Communication. New York: Palgrave, 1996. 409 p.

11. Adler P. S. Beyond Cultural Identity: Reflections on Cultural and Multicultural Man // Intercultural Communication: A Reader. Belmont. CA: Wadsworth, 1987.

12. Hammer M. R. Behavioral dimensions of intercultural effectiveness: a replication and extension // International Journal of Intercultural Relations, 1987. Vol. 11. P. 65-88.

13. Vaganova O. I. Case study in professional training. [Electronic resource]. URL: https://vgipuvaganova.files.wordpress.com/ .../d0b2d0b0d0b3d0b0d0bdd0bed0b2d0b (reference date: 27.11.2017).

14. Zheltova E. P. Case-study as a means of developing a communicative competence of technical university students." Bulletin of the Faculty of Humanities of St. Petersburg State University named after. prof. M. A. Bonch-Bruevich. №9. St. Petersburg, 2017. P. 87-93.

Поступила в редакциию 19.02.2018 2. 